\title{
Height-zoning change of residential buildings in contemporary urbanism with respect to daylight and insolation
}

\author{
Agnes Iringová ${ }^{1, *}$, Ján Rybárik ${ }^{1}$ \\ ${ }^{1}$ University of Žilina, Faculty of Civil Engineering, Slovakia
}

\begin{abstract}
The paper focuses on legislatively allowable amount of external shade by proposed height-zoning change of a structure and its impact on distribution of daylight and direct sunlight, light comfort, and insolation time in affected areas in dependence on their orientation. It also deals with a volume solution in terms of hygienic conditions in such residential buildings.
\end{abstract}

\section{Introduction}

Daylight is one of the primary aspects of a healthy environment. Any restriction under the allowable limit worsens hygienic condition of the affected area. In addition, of course, to sell such flats is not easy. External shading has a major impact on the availability of diffused light in shaded areas, and on light comfort in residential or work areas. Extensions, additions, and new housing development are barriers to already existing buildings and its collector areas, keeping them from transfer of global solar radiation. It causes reduction in daylight intensity, insolation, and passive solar gain in affected rooms.

The paper is aimed at examining to what extent the actual legislative limits are "hygienically correct" in relation to the residential environment and occupants of affected areas, i.e. the extent of required hygienic limits that are to be met after shading and taking apartments to use. It will try to find a compromise of a volume solution in case studies in order to optimize the relationship between the right of occupants to daylight and sustainable economic interest of developers entering into the residential area. The issue is very topical, since densification of urban structures by extensions or additions in the cities as well as in the country is still ongoing and affects all ages.

\section{Legislatively allowable amount of shade by designed structure in terms of daylight}

The effect of designed buildings on the existing environment in terms of availability of diffused light on the facade is specified in Regulation 259/2008 determining criteria and

* Corresponding author: agnes.iringova@,fstav.uniza.sk 
methodology of assessment given in STN 730580 Daylight in Buildings 1,2, Change 2 from 2000. The criterion for allowable daylight amount is the equivalent shade angle depending on the position and angle of the assessed area. Affected windows in the living and working areas are subjects of assessing.

Regulation 259/2008 requires the implementation of designed buildings not to make interior daylight conditions in nearby buildings worse than it is set in STN 730580 Daylight in Buildings 1,2, Change 2 from 2000. The allowable change or maximal amount of shade, determined by maximal equivalent shade angle, or, in cases where allowable amount of shade goes beyond the limit - e.g. gap sites, the criterion is equivalent sector shade angle in the boundary area of the building site. Values of allowable equivalent angles are based on existing conditions of urban planning. The highest allowable amount of external shade in historic city zones is $42^{\circ}$; camber ratio to the distance of the opposite building 1: 1 was applied in historic buildings, and subsequently clearances and window heights in the lowest-floor rooms were adjusted. Window heights from ground floor to higher floors were typically changed. [1]

The allowable amount of external shade in the second zone is $36^{\circ}$. It comprises facades of buildings situated in highly attractive locations, which brings owners' requirement to increase the value their estate. It primarily refers to zones near urban historic centres and busy streets attractive to investors, whilst the amount of shade allowed there is only towards the street; as for yards, it is up to $30^{\circ}$. Generally, applicable amount of external shade for all other areas is maximally $30^{\circ}$. Exceptions are affected faces of nursery and primary schools, where the maximal allowable equivalent shade angle is $25^{\circ}$. Such amount of external shade, if the window and room geometry is optimally designed, produces a presumption that the value of daylight factor after shading will be met.

\section{Volume solution of an apartment building with a superstructure in an urban area within legislative limits and its impact on light comfort in affected flats}

Allowable amount of external shade is one of the criteria that have significant impact on light comfort in affected or designed areas in terms of daylight intensity. It is possible to define it as the primary assumption affecting optimization of window area, its positioning and slope in the wall. Lower shade by built horizon also affects the structure and positioning of façade elements as well as room geometry itself. As for new buildings, in dependence on the site with allowable amount of external shade, the parameters can be optimized so that the required criteria of light comfort would be met. Buildings raised by 2000 , when designs went out of the boundary conditions of urban density of that time, contain window design, room geometry, and face structure optimized for their specific criteria. The change in these criteria - currently allowed higher amount of external shade often worsens light comfort in affected flats bellow the hygienic limits.

\subsection{Optimization of a superstructure volume solution within legislative limits}

The developer's requirement was to design legislatively maximal volume of a superstructure, built on existing apartment building, in respect to affected apartment buildings in the suburb. Boundary conditions were as follows: spacing between the affected opposite apartment building and the designed superstructure should be about $28 \mathrm{~m}$; it should affect northern face of the building. 
The one side of an extended apartment building is parallel with a similar existing apartment building; its opposite side faces the enclosed yard with a playground. It is one of four residential buildings enclosing and bordering the yard area.

The building with superstructure is located in the residential zone in Ružinov, where allowable amount of external shade is currently max $30^{\circ}$. The previous allowable amount of external shade in original urban disposing of residential buildings was about $20^{\circ}$. The superstructure volume solution, as requested by the investor, was optimized to the maximal allowable amount, which, according to legislation, enabled to build the 3 -storey superstructure with the receding top storey. Side shading by other buildings, in terms of their distance, is insignificant for assessed flat areas.

\subsection{Impact of allowable amount of external shade by superstructure on light comfort in affected flats}

The example to illustrate the impact of allowable amount of external shade on light comfort in affected flats is the first floor in the apartment building raised in 1970s in housing area. Windows of one room in each 3-room flat in this building face the planned superstructure; the flats are east/west-oriented.

Room and window geometry was designed to comply required hygienic limits; current conditions in all affected rooms met required daylight factor - see Fig. 3a. After the implementation of a 3-storey superstructure having allowable equivalent shade angle $30^{\circ}$, the value of daylight factor (DF) in the middle of the affected rooms will reduce by approximately $50 \%$ when compared to original conditions. The required hygienic limit will be met in the shallowest room only, its depth is $3.5 \mathrm{~m}$. Light conditions in all 10 flats on the first floor will be worse.

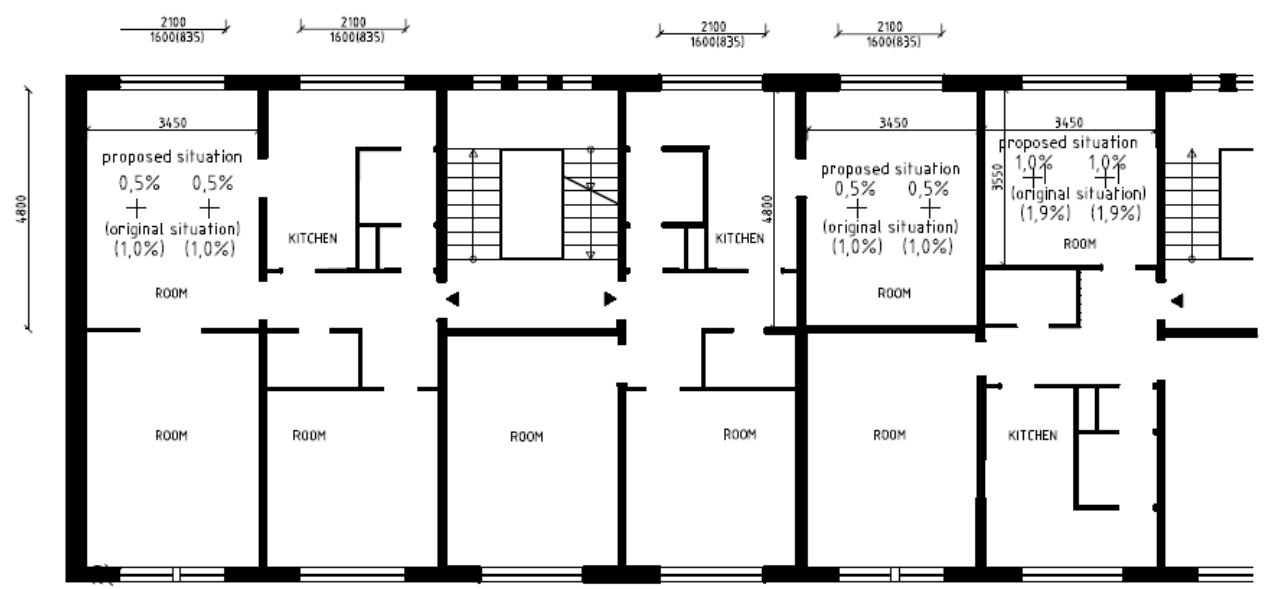

Fig.1 . Floor plan section of affected flats on the first floor

Affected flats on the 2nd floor, wherein equivalent shade angle under allowable amount of external shade is $28.2^{\circ}$, will have the DF value in critical rooms also below the limit - approximately $0.8 \%$, which is $11 \%$ below required limit.

Affected flats on the 3rd floor, wherein equivalent shade angle under allowable amount of external shade is $23.8^{\circ}$, will have the DF value in critical rooms within the limit with an average DF higher than $0.9 \%$. Daylight reduction in affected flats below the current legislative limits defined by equivalent shade angle is significantly higher than its specification in the original restriction before 2000. It weighs against their occupants. 
Table 1 Daylight reduction in critical rooms on the 1st floor

\begin{tabular}{|c|c|c|c|c|c|}
\hline \multirow{2}{*}{$\begin{array}{l}\text { Amount of } \\
\text { shading } \\
\text { equivalent shade } \\
\text { angle (ESA) }\end{array}$} & \multirow[t]{2}{*}{ Floor } & \multicolumn{2}{|c|}{$\begin{array}{c}\text { Average daylight } \\
\text { factor (DF) } \\
\text { in } \% \\
\end{array}$} & \multicolumn{2}{|c|}{$\begin{array}{l}\text { Daylight reduction - from } \\
\text { minimal standard } D F=0,9 \%\end{array}$} \\
\hline & & Room 1 & Room 2 & Room 1 & Room 2 \\
\hline \multirow{2}{*}{$\begin{array}{l}\mathrm{ESA}=20^{\circ} \\
\text { original situation }\end{array}$} & $1 \mathrm{st}$ & $1.00 \%$ & $1.9 \%$ & - & - \\
\hline & 2 nd & $1.35 \%$ & $2.30 \%$ & - & - \\
\hline \multirow{2}{*}{$\begin{array}{l}\mathrm{ESA}=30^{\circ} \\
\text { proposed situation }\end{array}$} & $1 \mathrm{st}$ & $0.50 \%$ & $1.0 \%$ & $50 \%$ & - \\
\hline & 2 nd & $0.785 \%$ & $1.54 \%$ & $13 \%$ & - \\
\hline \multirow{2}{*}{$\begin{array}{l}\mathrm{ESA}=25^{\circ} \\
\text { optimized situation }\end{array}$} & $1 \mathrm{st}$ & $0.80 \%$ & $1.5 \%$ & $11 \%$ & - \\
\hline & 2nd & $0.95 \%$ & $1.8 \%$ & - & - \\
\hline
\end{tabular}

\section{Legislatively allowable amount of external shade by designed structure and its impact on insolation time in affected rooms}

The second criterion restricting setting and volume solution of the designed home building amount of external shade in the area in relation to the housing environment - is the minimal required insolation time in affected flats. This is specified by Regulation 259/2008 and criteria and methodology to assess is defined in STN 734301 Residential Buildings. Affected windows in the residential environment and in pre-school buildings are subjects of assessment. According to Regulation 259/2008, the implementation of new buildings is required not to worsen light conditions in living rooms, rooms in children's and retirement homes, as well as rooms in similar facilities used for long-term stay of persons by more than it is admitted in STN 734301 Residential Buildings.

Shaded living rooms are required to have minimal insolation time 1.5 hours over a period from 1st March to 21st June when the sun is higher than $18^{\circ}$.

The exception can be only applied on residential buildings located in historic parts of cities, where insolation can be reduced to 1 hour in particular cases (construction work, building in gap sites etc.) as defined in Section 4.2.1.2 of STN 734301.

For pre-school facilities, the required minimal insolation time must not drop under 3 hours within 10:00 am - 15:00 pm due to external shading, whilst the implementation of newly built structures must not reduce the size of sunlit surface area of pre-school facilities by less than $50 \%$ of its total area. If the current sunlit window surface of playrooms is smaller than $50 \%$, it not allowed being more shaded.

\section{Allowable amount of external shade and its impact on insolation of affected rooms}

Depending on the orientation of the affected facade, its insolation time changes according to allowable amount of shade. In the particular case, the equivalent sector shade angle in checkpoint $1.2 \mathrm{~m}$ above the floor is $32.7^{\circ}$. Here is the example of the situation where westfacing windows in shaded rooms of affected flats would have equal amount of external shade. Insolation time in a critical position - with the largest sector of shading depending on window orientation is in Table. 2. Effect of an obstacle on shading the affected facade is in Fig. 4, wherein the dotted line means the sun's path according to solar time. It follows that on the critical day 1st March, east- and west-facing windows are strongly affected by 
shading collector areas and insolation time is about 1 hour, i.e. hygienic limits would not be met.

When the room is ideally oriented and contains south-faced windows, insolation time is only 2.25 hours. When facades are east-or west-oriented as well as when they are northeastor northwest-oriented, the insolation time is under hygienic limits.

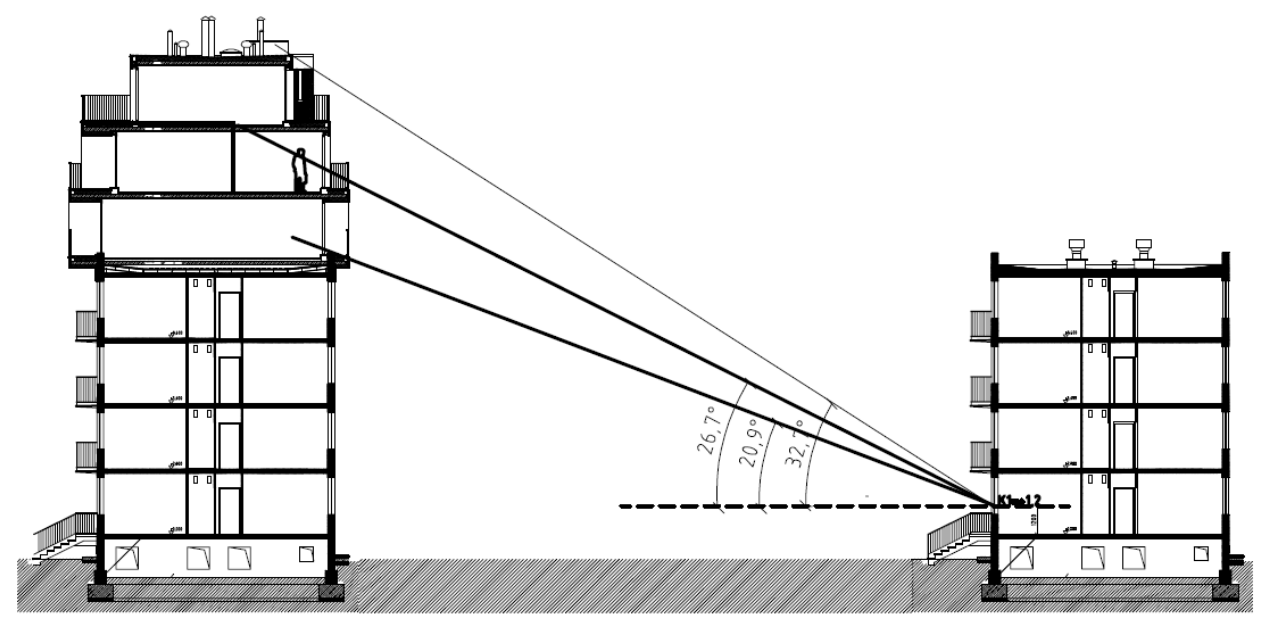

Fig. 2 Insulation - cross-section of superstructure and affected building - shade angles under the current, designed, and optimized conditions

Table 2 Insolation time at allowable amount of external shading in terms of daylight distribution

\begin{tabular}{|l|c|c|c|c|c|c|}
\hline \multirow{2}{*}{$\begin{array}{c}\text { Amount of } \\
\text { shading } \\
\text { equivalent shade } \\
\text { angle (ESA) }\end{array}$} & \multirow{2}{*}{$\begin{array}{c}\text { Critical } \\
\text { checkpoint } \\
\text { position }\end{array}$} & \multicolumn{5}{|c|}{ Window orientation } \\
\cline { 3 - 7 } & & \multicolumn{5}{|c|}{ Insolation time (hours), 1.3. 49 north latitude } \\
\cline { 3 - 7 } & south & southeast & southwest & east & west \\
\hline $\begin{array}{l}\text { ESA=20.9 } \\
\text { original situation }\end{array}$ & $\mathrm{K} 1$ & 8 & 4 & 4 & 1.75 & 1.75 \\
\hline $\begin{array}{l}\text { ESA=32.7 } \\
\text { proposed situation }\end{array}$ & $\mathrm{K} 1$ & 2.5 & 2 & 2 & 0.5 & 0.5 \\
\hline $\begin{array}{l}\text { ESA=26.7 } \\
\text { optimal situation }\end{array}$ & $\mathrm{K} 1$ & 6 & 2.75 & 2.75 & 1.5 & 1.5 \\
\hline
\end{tabular}




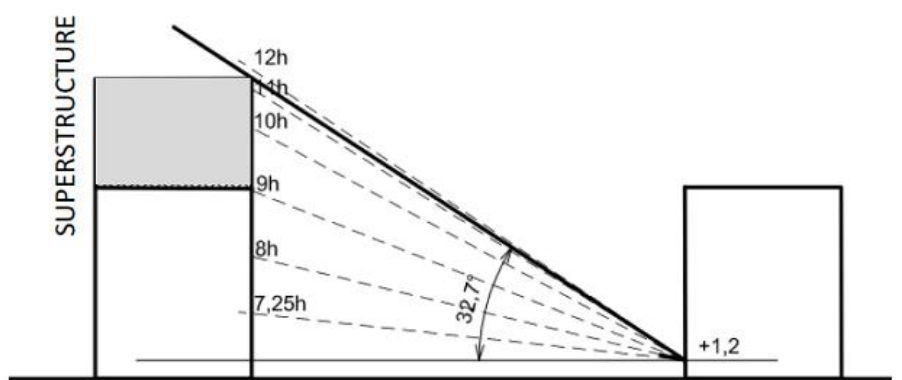

Fig. 3 Cross-section of sun height depending on solar time

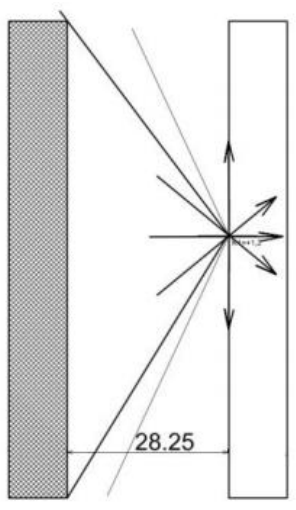

Fig. 4 Situation

In the specific project solution, the affected facade was east-faced and affected flats were those with more than $1 / 3$ west-oriented floorage. In this case, since the west-facing windows were free of the horizon, and required insolation time in rooms with windows oriented to this cardinal point met hygienic limits; shaded side did not have to be sunlit according to legislation. To design the superstructure volume, only amount of shade on the window wall was crucial in terms of diffuse light, allowing building the superstructure within allowable limits according to STN 730,580. [2]

\section{Optimization of the superstructure volume solution in terms of sustainable hygienic quality in affected flats}

Considering aforementioned statements, it is of all-society interests to re-evaluate current limits for external shading and to specify legislatively acceptable hygienic level, at least in relation to the residential environment.

The optimal solution for assessed condition and for similar boundary conditions of housing development in suburbs and individual built-up zones, allowable amount of external shade would be up to $25^{\circ}$.

Based on this assumption, rooms on the first floor in the assessed building would have daylight intensity reduced by approximately $25 \%$ when compared to standard limits see Fig. 5. The impact on final insolation time would be also positive when east/westoriented.

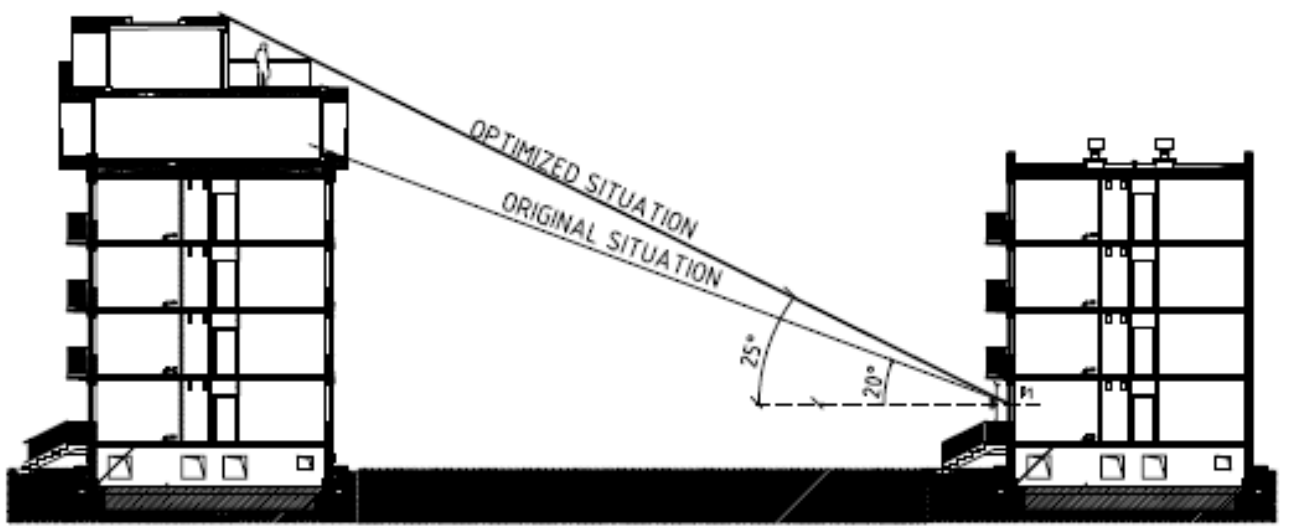

Fig. 5 Cross-section with optimized superstructure volume in relation to affected flats 


\section{Conclusion}

In terms of daylight, allowable amount of reduced daylight is significantly higher on a comparative level than admitted in legislation by 2000. Up to that time, maximal allowable reduction of daylight factor was $15 \%$ on a comparative level in contrast to hygienic limits. At present-day methodology, the current amount of daylight reduction is really depending on boundary conditions compared to a standard limit of about $50 \%$. In zones with higher allowable amount of shade - wider city centre and central urban areas - the impact on light comfort in affected flats is even more considerable. Flats on the 1st to 3rd floors often become the flats without daylight.

According to contemporary methodology, the only criterion to assess through equivalent shade angle is external illuminance on the outside in the middle of a shaded window. The legislation admits high-loyal limits to investors, but less-loyal ones to occupants and owners of such estates. It is of all-society interests to optimize these conditions in such a way that hygienically acceptable level would be reached to benefit of all concerned taxpayers.

The optimal solution for assessed condition, as well as for similar boundary conditions in housing development and zones with individual housing construction, would be strictly set requirements for maximal equivalent shade angle up to $25^{\circ}$.

In that situation daylight intensity in shaded rooms on the first floor in affected building, investigated in the case study, would be reduced approximately by $11 \%$ from limit value - see Table 1. On the upper floors, the value of daylight factor would meet hygienic limits.

Insolation in rooms with east- or west-oriented windows at this amount of external shade would be about 1.5 hours, which is the lower line of hygienic limits. The impact on current hygienic conditions in existing flats would not be so critical. This shading restriction would largely influence intensity of direct irradiance in terms of passive or active making use of collector areas in reducing energy demands of these buildings.

\section{Acknowledgement}

Presented results were obtained with the support of the grant project VEGA no. 1/0945/16 (KEGA no. 041ŽU-4/2014).

\section{References}

1. P. Durica, Failure buildings ( EDIS, Žilina, 2012)

2. M. Halahyja, Building heat engineering, acoustics and lighting (ALFA/SNTL,1985) 